West region

Bristol Marriage and Family Guidance Council, 75 Whiteladies Road, Bristol BS8 2NT (Tel. Bristol $3^{12316)}$

Bath and District Marriage Guidance Council, Gascoyne House, Upper Borough Walls, Bath BAI IRN (Tel. Bath 65593)

Southampton and District Marriage Guidance Council, 32 West Park Road, Southampton SOI 2 AS (Tel. Southampton 29761)

Oxfordshire Marriage Guidance Council, 33 Iffley Road, Oxford OX 4 IEA (Tel. Oxford 42960)

\section{East region}

London Marriage Guidance Council, 76a New Cavendish Street, Harley Street WIM 7LB (Tel. or-580 ro87)

|North West region

Manchester Marriage Guidance Council, Gaddum Centre, 274 Deansgate, Manchester M3 ${ }_{4} \mathrm{HB}$ (Tel. $061-8349163 / 4834$ )

Preston and District Marriage Guidance Council, 160 Garstang Road, Fulwood, Preston (Tel. Preston 717597)

Northern Ireland Marriage Guidance Council, 76 Dublin Road, Belfast BT2 7 HP (Tel. Belfast 23454)

North East region

Rotherham Marriage Guidance Council, 8 Percy Street, Rotherham (Tel. Rotherham 77644)

South Humberside Marriage Guidance Council, 4 Dudley Street, Grimsby (Tel. Grimsby 54392)

South region

Croydon and District Marriage Guidance Council,
- 9 Ramsey Court, Church Street, Croydon CRo I9RF (Tel. or-680 1944)

\section{Midland region}

Coventry and District Marriage Guidance Council, Gorton House, 11 Priory Row, Coventry CVI 5 EX (Tel. Coventry 25863)

Northamptonshire Marriage Guidance Council, 24 Hazelwood Road, Northampton NNI ILN (Tel. Northampton 34400)

Nottinghamshire Marriage Guidance Council, 84 Mansfield Road, Nottingham NGI $3 \mathrm{HD}$ (Tel. Nottingham $578{ }_{3} 6$ )

Leicester and Leicestershire Marriage Guidance Council, 94 London Road, Leicester LE2 oQS (Tel. Leicester 54301 I)

Birmingham Marriage Guidance Council, 71 Broad Street, Birmingham B 15 IAQ (Tel. 02 1-643 1638)

* Lichfield Marriage Guidance Council, Frogmorton House, Frog Lane, Lichfield, Staffs (Lichfield 52760)

* South Warwickshire Marriage Guidance Council, 33 Regent Grove, Leamington Spa (Tel. Leamington Spa 24899)

Herefordshire Marriage Guidance Council, 4a St. Owen Street, Hereford (Tel. Hereford 6023)

Burton-upon-Trent Marriage Guidance Council, 27 Union Street, Burton-upon-Trent DEI4 IAG (Tel. Burtonupon-Trent 61697)

* Rugby Marriage Guidance Council, 35a Regent Street, Rugby (Tel. Rugby 65675)

* Kettering Marriage Guidance Council, (outpost) (Tel. Northampton 34400)

*Denotes single therapy (not co-therapy).

\title{
FORTHGOMING EVENTS
}

\section{Institute of Family Therapy}

Supervision Workshops in Family Therapy, intended for those who have attended an introductory course and have had some clinical experience in family therapy, will be held on Wednesday mornings for 20 sessions, beginning on 17 January. Further details and application forms from Ms Alex Lowe, Institute of Family Therapy, 5 Tavistock Place, London, W.C.r.

\section{Henderson Hospital}

A ten-session day release course in Group Work will be held at the Henderson Hospital on Thursdays, January-March 1979. For particulars and application form write to the Group Work Course Secretary, Henderson Hospital, 2 Homeland Drive, Brighton Road, Sutton, Surrey SM2 5 LT.

\section{Institute of Child Health}

A one-week course in Child Psychiatry, organized by the Institute of Child Health in conjunction with members of the staff of the Hospital for Sick Children, Great Ormond Street, will be held from 26 February-2 March. Application forms from: The Sub-Dean, Institute of Child Health, 30 Guildford Street, London WGrN IEH.

\section{Institute of Family Psychiatry}

A two-day course in Family Psychiatry intended for psychiatrists will be held on 20 and 21 June 1979, at the Institute of Family Psychiatry, Ipswich. Programme and application form from the Institute, The Ipswich Hospital, 23 Henley Road, Ipswich IPI 3 TF. 